\title{
EDITORIAL
}

\section{More pressure on pulmonary hypertension}

\author{
M. Humbert
}

$\mathrm{T}$ he European Respiratory Review is structured around a "theme of the month". I am delighted to introduce pulmonary hypertension $(\mathrm{PH})$ as the first theme of the new Review.

PH describes a group of devastating diseases, comprising idiopathic and associated/secondary forms, which cause breathlessness, loss of exercise capacity and death due to elevated pulmonary artery pressure and subsequent right heart failure [1]. Pulmonary arterial hypertension (PAH) is defined by an elevation of the mean pulmonary artery pressure above $25 \mathrm{mmHg}$ at rest and/or $30 \mathrm{mmHg}$ during exercise without elevation of the pulmonary capillary wedge pressure ( $\leqslant 15 \mathrm{mmHg}$ ) [1]. The underlying pathophysiological mechanism is extensive pulmonary artery remodelling [2]. PH was previously classified into two categories, namely primary or secondary $\mathrm{PH}$, depending on the absence or presence of identifiable causes or risk factors [1]. In the second (1998), third (2003), and fourth (2008) World Symposium on PH, a detailed clinical classification of the disease was agreed upon. The 2003 version is shown in table 1 [1]. The main subcategories share similarities in pathogenetic mechanisms, clinical presentation and therapeutic options, allowing clinicians to conduct trials using homogeneous groups of patients. Similarly, basic science specialists have attempted to describe pathophysiological mechanisms in the same homogeneous groups of patients with $\mathrm{PH}$.

\section{PAH}

This includes cases without identifiable cause or risk factors, so-called idiopathic PAH (sporadic appearance) and familial PAH [1]. For these subgroups, mutations in the bone morphogenetic protein (BMP)/transforming growth factor- $\beta$ superfamily (BMPR2, activin receptor-like kinase-1 and endoglin) are now known to play a crucial role [3]. However, genetic/environmental factors are likely to be the "double hit", favouring the start of the disease [2]. The other subgroups include a number of conditions or diseases of known causes associated with the appearance of PAH [1]. Among the associated conditions, connective tissue disorders such as systemic sclerosis are major causes of $\mathrm{PAH}$, with $>10 \%$ of systemic sclerosis patients developing this severe life-threatening complication [4]. All PAH forms have the localisation of remodelling lesions to the small pulmonary muscular arterioles in common [2]. In addition, they may be linked with significant venous or capillary involvement, namely pulmonary venoocclusive disease and pulmonary capillary haemangiomatosis, conditions characterised by a certain degree of refractoriness to usual $\mathrm{PAH}$ therapies $[1,5]$.

\section{PH WITH LEFT HEART DISEASE}

This category consists predominantly of left-sided valvular or myocardial diseases, exerting mechanical strain on the pulmonary vasculature due to congestion [1]. Such conditions passively affect the pulmonary vasculature and are not usually part of the research priorities of the respiratory community. Nevertheless, studies are now focusing on this subgroup of patients who may sometimes develop severe pulmonary vascular disease.

\section{PH ASSOCIATED WITH LUNG DISEASES AND/OR HYPOXIA}

Within this category, the predominant cause is inadequate oxygenation of arterial blood as a result of either lung disease, impaired control of breathing or residence at high altitude [1]. Hypoxia-driven molecular mechanisms presumably play an important role in this group, but it remains unclear why some patients develop severe out of proportion $\mathrm{PH}[6,7]$. In addition, inflammatory mechanisms linked to the lung disease may contribute to the development of the pulmonary vascular disease [8]

\section{PH DUE TO CHRONIC THROMBOTIC AND/OR EMBOLIC DISEASE}

This category includes either chronic thromboembolic PH [9] due to proximal organised material in large pulmonary arteries, which can benefit from pulmonary endarterectomy, or more peripheral obstruction similar to those appearing in the small vessels in idiopathic PAH [9]. Abnormalities of coagulation and fibrinolysis control are assumed to represent the decisive trigger events [9].

\section{MISCELLANEOUS}

This category involves PH linked with various, mostly inflammatory, disorders. Sarcoidosis and histiocytosis $\mathrm{X}$ represent major conditions in this subgroup [1].
CORRESPONDENCE

M. Humbert

Université Paris-Sud 11, Service de Pneumologie et Réanimation Respiratoire, Hôpital Antoine Béclère Assistance Publique Hôpitaux de Paris

157 rue de la Porte de Trivaux 92140 Clamart

France

Fax: 33146303824

E-mail: marc.humbert@abc.aphp.fr

Received:

January 032009

Accepted

January 032009

STATEMENT OF INTEREST

None declared.

PROVENANCE

Submitted article, peer reviewed. 
Epidemiological data are not available for the entire field of $\mathrm{PH}$. The largest and most recent national registries on $\mathrm{PAH}$ have been reported in 2006 in France [10] and 2007 in Scotland (UK) [11]. Prevalence rates for PAH as a whole vary among regions in France, ranging from five cases per million per year to 25 cases per million per year [10]. Data from Scotland indicate a prevalence ranging from 26 to 52 cases per million [11]. In addition, three quarters of the detected cases are in New York Heart Association functional class III or IV when diagnosed, a stage at which survival is limited despite available treatments [10]. Similar results have been reported in the USA by the Chicago group [12]. This information supports the fact that early detection should be promoted in high-risk populations, and that $\mathrm{PH}$ should be considered and screened for in patients displaying symptoms, such as unexplained dyspnoea. With a yearly incidence of two per million, PAH fulfils the criteria of a rare disease, with a higher appearance in females compared with males and a mean age at diagnosis of $<50$ yrs [10, 13]. Sex differences are also true for other categories of the disease, such as connective tissue disease-associated $\mathrm{PAH}$, which is much more frequent in females compared with males [10].

Survival of untreated idiopathic familial PAH is extremely poor, with median survival ranging from 2 to 3 yrs [14]. This is similarly true for many other categories of $\mathrm{PH}$, such as connective tissue disease-associated cases [15]. Over the past few years, various therapeutic strategies have been developed, which include different types of prostanoids, endothelin-receptor antagonists and phosphodiesterase inhibitors [16-19]. These agents were shown to relieve dyspnoea, improve exercise capacity and, not proven for all approaches, survival in these patients [16]. Nevertheless, we are still far from curing $\mathrm{PH}$ and further progress in drug development is urgently needed to achieve long-term survival with better quality of life.

$\mathrm{PH}$ has a multifactorial pathobiology. Next to vasoconstriction and in situ thrombosis, remodelling of all layers of the pulmonary vessel wall represents the hallmark of this disease, with proliferating resident cell types (endothelial, smooth muscle and adventitial fibroblasts), inflammatory cells and platelets, as well as circulating progenitor cells coming into close interplay [2]. Loss of endothelial function with lack of production of vasodilatory and anti-proliferative agents, such as nitric oxide and prostacyclin and their downstream cyclic nucleotides, was found to be a key event, providing a starting point for therapies based on these agents [2]. In contrast, potent vasoconstrictors, such as the endothelin-1 pathway, are known to be upregulated, again serving as a basis for novel therapeutic approaches [2]. Most importantly, going far beyond their immediate effect on vasomotor control, all these pathways have a major impact on the long-term balance of proliferation and apoptosis of the lung vascular cells, i.e. affect remodelling events [2, 20]. Notably, next to the resident vascular cell types involved in the remodelling, recruitment of circulating progenitor cells and different leukocyte types is controlled by these pathways and by an as yet only partially understood lung vascular chemokine system [8].

In the present issue of the European Respiratory Review, an update by SOUZA and JARDIM [21] will discuss novel information on several forms of pulmonary hypertension. In addition, other chapters will emphasise some important aspects of pulmonary vascular medicine, including pulmonary hypertension

\begin{tabular}{l} 
TABLE 1 Diagnostic classification of pulmonary \\
hypertension \\
Pulmonary arterial hypertension \\
Idiopathic \\
Familial \\
Associated with: \\
Connective tissue diseases \\
Congenital left-to-right shunt \\
Portal hypertension \\
HIV infection \\
Drugs and toxins \\
Other conditions ${ }^{\#}$ \\
Substantial venous or capillary involvement \\
Pulmonary veno-occlusive disease \\
Pulmonary capillary haemangiomatosis \\
Persistent pulmonary hypertension of the newborn \\
Pulmonary hypertension with left heart disease \\
Left-sided atrial or ventricular heart disease \\
Left-sided valvular heart disease \\
Pulmonary hypertension associated with lung disease or \\
hypoxaemia or both \\
Chronic obstructive pulmonary disease \\
Interstitial lung disease \\
Sleep-disordered breathing \\
Alveolar hypoventilation disorders \\
Chronic exposure to high altitude \\
Developmental abnormalities \\
Pulmonary hypertension due to chronic thrombotic or \\
embolic disease or both \\
Thromboembolic obstruction of proximal pulmonary arteries \\
Thromboembolic obstruction of distal pulmonary arteries \\
\hline Sarcoidosis, pulmonary Langerhans cell histiocytosis, \\
\hline
\end{tabular}

\#: these conditions include thyroid disorders, type-1 glycogen storage disease, Gaucher's disease, hereditary haemorrhagic telangiectasia, haemoglobinopathies, myeloproliferative disorders and splenectomy. Reproduced from [1] with permission from the publisher.

complicating hereditary haemorrhagic telangiectasia [22, 23], pulmonary hypertension in high-altitude residents [24], pulmonary hypertension in children [25], chronic thromboembolic pulmonary hypertension [26], and novel therapeutic strategies such as inhaled prostaglandins [27] and soluble guanylate cyclase stimulation, an emerging option in pulmonary hypertension therapy [28].

\section{REFERENCES}

1 Simonneau G, Galiè N, Rubin LJ, et al. Clinical classification of pulmonary hypertension. J Am Coll Cardiol 2004; 43: Suppl. 12, 5S-12S.

2 Humbert M, Morrell NW, Archer SL, et al. Cellular and molecular pathobiology of pulmonary arterial hypertension. J Am Coll Cardiol 2004; 43: Suppl. 12, 13S-24S. 
3 Sztrymf B, Coulet F, Girerd B, et al. Clinical outcomes of pulmonary arterial hypertension in carriers of BMPR2 mutation. Am J Respir Crit Care Med 2008; 177: 1377-1383.

4 Hachulla E, Gressin V, Guillevin L, et al. Early detection of pulmonary arterial hypertension in systemic sclerosis: a French nationwide prospective multicenter study. Arthritis Rheum 2005; 52: 3792-3800.

5 Montani D, Price LC, Dorfmüller P, et al. Pulmonary venoocclusive disease. Eur Respir J 2009; 33: 189-200.

6 Chaouat A, Naeije R, Weitzenblum E. Pulmonary hypertension in COPD. Eur Respir J 2008; 32: 1371-1385.

7 Sommer N, Dietrich A, Schermuly RT, et al. Regulation of hypoxic pulmonary vasoconstriction: basic mechanisms. Eur Respir J 2008; 32: 1639-1651.

8 Dorfmüller P, Balabanian K, Perros F, Humbert M. Inflammation in pulmonary arterial hypertension. Eur Respir J 2003; 22: 358-363.

9 Dartevelle P, Fadel E, Mussot S, et al. Chronic thromboembolic pulmonary hypertension. Eur Respir J 2004; 23: 637-648.

10 Humbert M, Sitbon O, Chaouat A, et al. Pulmonary arterial hypertension in France: results from a national registry. Am J Respir Crit Care Med 2006; 173: 1023-1030.

11 Peacock A, Murphy NF, McMurray JJV, Caballero L, Stewart S. An epidemiological study of pulmonary arterial hypertension in Scotland. Eur Respir J 2007; 30: 104-109.

12 Thenappan T, Shah SJ, Rich S, Gomberg-Maitland. A USAbased registry for pulmonary arterial hypertension: 19822006. Eur Respir J 2007; 30: 1103-1110.

13 Humbert M. The burden of pulmonary hypertension. Eur Respir J 2007; 30: 1-2.

14 D'Alonzo GE, Barst RJ, Ayres SM, et al. Survival in patients with primary pulmonary hypertension. Ann Int Med 1991; 115: 343-349.

15 Steen VD, Medsger TA. Changes in causes of death in systemic sclerosis, 1972-2002. Ann Rheum Dis 2007; 66: 940-944.
16 Humbert M, Sitbon O, Simonneau G. Treatment of pulmonary arterial hypertension. New Engl J Med 2004; 351: 1425-1436.

17 Gomberg-Maitland M, Olschewski H. Prostacyclin therapies for the treatment of pulmonary arterial hypertension. Eur Respir J 2008; 31: 891-901.

18 Dupuis J, Hoeper MM. Endothelin receptor antagonists in pulmonary arterial hypertension. Eur Respir J 2008; 31: 407-415.

19 Wilkins MR, Wharton J, Grimminger F, Ghofrani HA. Phosphodiesterase inhibitors for the treatment of pulmonary hypertension. Eur Respir J 2008; 32: 198-209.

20 Perros F, Montani D, Dorfmuller P, et al. Platelet derived growth factor expression and function in idiopathic pulmonary arterial hypertension. Am J Respir Crit Care Med 2008; 178: 81-88.

21 Souza R, Jardim C. Trends in pulmonary arterial hypertension. Eur Respir Rev 2009; 18: 7-12.

22 Shovlin CL, Gibbs JSR, Jackson JE. Management of pulmonary arteriovenous malformations in pulmonary hypertensive patients: a pressure to embolise? Eur Respir Rev 2009; 18: 4-6.

23 Montani D, Price LC, Girerd B, et al. Fatal rupture of pulmonary arteriovenous malformation in hereditary haemorrhagic telangiectasis and severe PAH. Eur Respir Rev 2009; 18: 42-46.

$24 \mathrm{Xu} X Q$, Jing ZC. High-altitude pulmonary hypertension. Eur Respir Rev 2009; 18: 13-17.

25 Beghetti M. Paediatric pulmonary hypertension: monitoring progress and identifying unmet needs. Eur Respir Rev 2009; 18: 18-23.

26 Lang IM. Managing chronic thromboembolic pulmonary hypertension: pharmacological treatment options. Eur Respir Rev 2009; 18: 24-28.

27 Olschewski H. Inhaled iloprost for the treatment of pulmonary hypertension. Eur Respir Rev 2009; 18: 29-34.

28 Ghofrani HA, Grimminger F. Soluble guanylate cyclase stimulation: an emerging option in pulmonary hypertension therapy. Eur Respir Rev 2009; 18: 35-41. 